corpo no aparato do Estado e direcione a organização das escolas dando poder real aos professores, alunos e pais, através de mecanismos que efetivem o envolvimento nas questões pedagógicas e administrativas estando estas últimas subordinadas aos princípios e necessidades pedagógicas e não o inverso.

Referências Bibliográficas:

FRIGOTTO, G. A Educação e a crise do capitalismo real. 2. ed. São Paulo: Cortez, 1995 PARO, V. H. Administração escolar: introdução crítica. São Paulo: Cortez e Autores

Associados, 1986

SAPELLI, M. L. S. Políticas educacionais do governo Jaime Lerner (1995-2002). Cascavel: Gráfica Igol, 2003.

SAVIANI, D. Pedagogia histórico-crítica: primeiras aproximações. 8. ed revista e ampliada. Campinas, SP: Autores Associados, 2003.

SOUZA, S. A. Gestão Escolar Compartilhada. Democracia ou descompromisso? São Paulo: Xamã, 2001.

Recebido em julho de 2007

Aprovado em agosto de 2007

\section{A terceirização na execução de políticas de alfabetização de adultos: \\ sobre escolas, igrejas e associações comunitárias.}

Gladys Beatriz Barreyro'

Resumo:

O trabalho mostra alguns achados de pesquisa acerca da implantação de um Programa de Alfabetização de Jovens e Adultos, o Programa Alfabetização Solidária, cujo modelo "terceirizava" em Instituições de Educação Superio (IES) sua implementação. Elas, por sua vez, nos Grandes Centros Urbanos, realizavam "parcerias" com outras instituições em cuja sede era realizada a alfabetização da população alvo. O trabalho foi realizado em uma IES privada

de um município próximo à cidade de São Paulo e a metodologia específica utilizada para investigar esse aspecto da pesquisa ${ }^{2}$ consistiu em entrevistas, observações de aula "in loco" e aplicação de um questionário auto-administrado. Os resultados assinalam que a abertura de salas de aula em ONG e demais instituições da comunidade mostra que, embora fosse conseguida a capilaridade necessária, perdia-se o cumprimento do objetivo do Programa.

Palavras-chave: Políticas educacionais; Terceirização; Programa Alfabetização Solidária; Instituições de Educação Superior; ONG. 


\section{Introdução}

$\mathrm{Na}$ América Latina, as políticas educacionais da década de 1990 foram fortemente influídas pelo modelo de Estado que estava sendo reformado. Assim, nos diversos países encontravamse repostas com lógicas semelhantes, advindas da agenda divulgada pelos organismos internacionais (Sottoli, 2000) embora permeadas com diferentes características sócio-culturais do país, com seus sistemas educativos e com a participação de suas classes políticas que atuavam como mediadoras ativas entre as recomendações e as políticas efetivas (Coraggio, 1997). Assim, as políticas sociais da década, reconfiguradas sob os eixos de descentralização, focalização e privatização (Di Pierro, 2001), são ressignificadas em cada pais.

No Brasil, o governo propunha, em 1997 uma reforma do Estado que incorporava como novidades o conceito de público não estatal (Bresser Pereira, 1998:262) e de organizações sociais. No âmbito das políticas sociais, concomitantemente com aquela reforma, era implantado Programa Comunidade Solidária que postulado como inovador, foi concebido como uma estratégia do Governo Federa para a gestão das políticas sociais: "... não se trata mais de um sinônimo de política governamental. Política pública é aquela que se realiza em espaço público, com o concurso de atores governamentais e não governamentais, estatais e não estatais" (Franco, 2000: 81)
Iniciava-se então um movimento de mudança na provisão de certos serviços e no atendimento de alguns direitos pelo Estado que visava promover um modelo de terceirização de políticas sociais, ainda hoje vigente.

- Comunidade Solidária elaborou Marco Legal do Terceiro Setor, a Lei 9790/99, que criou as Organizações da Sociedade Civil de Interesse Público-OSCIPs (Ferrarezi, 2000; Falcão e Cuenca, 1999), favorecendo o processo de terceirização de políticas sociais (Barreyro, 2006), contando com financiamento do BID para essas ações.

Já o Programa Alfabetização Solidária fo um dos projetos inovadores da Comunidade Solidária, que desenvolveu também Universidade Solidária e o Capacitação Solidária (Franco, 2000), e sempre manteve relação com ela.

\section{Características do Programa} Alfabetização Solidária

O Programa Alfabetização Solidária foi criado em 1997 funcionando em municípios do Norte e Nordeste e em Grandes Centros Urbanos. Seu modus operandi consistia no estabelecimento do que chamava "parcerias" com Instituições de Ensino Superior (IES) que implementavam a proposta de alfabetização. As Instituições, por meio de coordenadores escolhidos para trabalhar com o Programa, selecionavam capacitavam os alfabetizadores a cada semestre para que esses ministrassem cinco meses de aulas nas quais desenvolviam a proposta de alfabetização.
Uma vez acabado o semestre, o Programa iniciava um novo módulo com novas salas de aula, novos alfabetizadores e novos alfabetizandos. $70 \%$ das Instituições participantes eram privadas e $30 \%$ públicas em 2003. Do total de IES, 30\% funcionavam no Estado de São Paulo.

O Programa era financiado com recursos advindos de doações de empresas e de cidadãos (da campanha "adote um analfabeto") que, segundo o Programa cobriam $50 \%$ do custo/aluno/ano e com fundos governamentais (50\% do custo/ aluno/ano)

Os recursos do governo federal foram R\$ 107.000.000,00 em 2002 (MEC, 2004). Alfabetizadores e coordenadores recebiam "bolsas" dentre $\mathrm{R} \$ 120,00$ e $\mathrm{R} \$ 300,00$ por mês.

Até 2003, o Programa contava com 2.010 municípios participantes, 135 empresas financiadoras, 219 Instituições de Ensino Superior Participantes e 4.000.000 de alunos "atendidos". Os alunos "atendidos" significavam $26 \%$ da população analfabeta do país de 15 anos ou mais. Dentre esses alunos 20 e $24 \%$ evadiram-se do curso (Programa Alfabetização Solidária, 2002c: $14)^{5}$

Desde novembro de 1998, um ano após iniciado, o Programa era gerido pela Associação de Apoio ao Programa Alfabetização Solidária - AAPAS. (www. alfabetizacaosolidaria.org, acessado em 3/12/2001)

Também existia um Conselho Consultivo de Pró-reitores das Instituições de Ensino
Superior participantes, esse com caráter de assessoramento.

\section{- Programa Alfabetização Solidária} nos Grandes Centros Urbanos: IES Entidades parceiras

Para a implementação das salas de aula do Projeto Grandes Centros Urbanos, as Instituições de Ensino Superior realizavam parcerias com diversas entidades que tinham acesso às camadas da população analfabeta, tais como escolas, igrejas, associações comunitárias e de moradores.

Para conhecer a articulação entre essas entidades e as IES foram utilizadas nesta pesquisa as seguintes fontes de informação: 1) questionários enviados para as entidades; 2) observações das aulas realizadas in situ; 3) entrevistas com autoridades dessas entidades; 4) entrevistas com adultos que freqüentavam algumas das salas de aula. As informações foram sistematizadas pela triangulação das três fontes: entrevistas, questionários e observações.

O estudo foi realizado numa IES situada num município próximo à Cidade de São Paulo $^{6}$ Essa Instituição priorizou às que chamava de ONGs, num sentido amplo mas que, a rigor, eram ONGs de base organizações religiosas (católicas evangélicas) e escolas, com as quais já inha relações anteriores na implementação de outros projetos. Posteriormente, foram incluídas outras associações da região (Zona Leste) e oito municípios da Grande São Paulo, na região do Alto Tietê. 
Dentre as instituições parceiras predominavam as associações de bairro sendo importante também o número de igrejas que participavam: respectivamente 13 associações de bairro, 6 escolas ( 1 delas privada), 6 paróquias da igreja católica, 3 igrejas evangélicas, um asilo e um CAMEF (Centro de Apóio ao Menor e à Família) A IES defendia essa preferência porque

"... permite abrir salas na periferia e pelo fato de a capacitação formar alfabetizadores do lugar que, uma vez fechada a sala, ficam no local, que, uma vez fechada a sala, ficam no local, capacitados. Potencialmente esse alfabetizador liderança comunitária" (Coordenadora da IES)

A parceria consistiu, por parte das instituições da comunidade, na provisão de espaço: uma sala com móveis aptos para a alfabetização (a seleção que uma Instituição de Ensino Superior fazia incluiu uma inspeção para comprovar a existência de condições mínimas de funcionamento: banheiros etc.)

O contato entre as entidades e a IES para a realização da alfabetização foi iniciativa das primeiras em alguns casos e, em outros, foi o próprio (futuro) alfabetizador que contatou a IES, ou porque já trabalhava com alfabetização ou para iniciar as tarefas. 0 jornal da cidade, a propaganda na TV local, um conhecimento direto do trabalho da Instituição (ex-alunos, alunos) foram outras formas pelas quais as entidades souberam do Programa Alfabetização Solidária.

As entidades participantes declaravam ter fins variados: além das escolas, cuja atividade específica é a educação, existiam outras finalidades declaradas relacionadas com ajuda social. Assim, as igrejas, cuja função é a evangelização, também realizavam serviços pastorais de "ajuda aos necessitados". Asassociações comunitárias declaravam, entre suas funções: "ajuda a pessoas carentes da comunidade", "reuniões de amigos de bairro", "promoção de festas e reuniões" e "assistência social a crianças, idosos e adultos", "trabalhar com os pais em famílias desestruturadas que não têm conhecimentos". A educação também era mencionada como uma das funções dessas associações e, aliás, a própria alfabetização: "Ajudar na alfabetização de dultos e adolescentes da comunidade em geral", "alfabetizar jovens e adultos que não sabem ler e escrever".

As associações de bairro ofereciam, também, cursos de ginástica, cabeleireiro, artesanato, reforço escolar para os seus associados, cobrando uma mensalidade. Algumas delastambémrecebiamprogramas governamentais: Leve Leite, Jovem Cidadão etc. Em geral, as atividades das associações e das igrejas eram realizadas por voluntários. Excepcionalmente foram incluídas entidades como asilo ambulatório de saúde mental, questões que serão analisadas mais à frente.

Os motivos que as instituições parceiras declaravam tê-las levado a realizar a parceria com as Instituições de Ensino Superior para desenvolver o Programa podem se classificar em dois tipos:

(a) Motivos relacionados a benefícios

\section{materiais que a IES poderia trazer, tais com}

-materiais didáticos do ProgramaAlfabetização Solidária (cartilhas, cadernos, lápis etc) e merenda escolar;

- atividades extra, tais como palestras com dentistas, médicos etc., que a Instituição de Ensino Superior levaria às entidades como parte de conteúdos incluídos no Programa Alfabetização Solidária;

- capacitação dos alfabetizadores realizada pelos professores da IES, que beneficiaria a formação dos voluntários que trabalham nas entidades;

- verbas para pagamento do trabalho dos alfabetizadores-voluntários;

falta de escolas próximas impedindo à população de contar com aulas de alfabetização.

\section{(b) Motivos relacionados com valores,}

\section{tais como:}

combate ao analfabetismo;

demanda por cursos de alfabetização

- necessidade de conscientizar a comunidade.

As instituições raramente declaravam ter recebido benefícios elas mesmas. Só excepcionalmente era reconhecido algum benefício: "A divulgação da própria comunidade no sentido de evangelização e catequistas mais preparados que mal sabiam ler"; "Para a instituição é ver os pais dos alunos da escola, lendo e escrevendo, participando mais na escola". "Os alfabetizadores [que já trabalhavam na instituição] agora estão bem preparados". Geralmente, tendia-se a assimilá-los aos benefícios recebidos pela população: "... as pessoas do bairro que foram beneficiados", "melhorou a autoestima", "Já temos alunos na tele-sala".

A avaliação da parceria com as Instituições de Ensino Superior era positiva por parte das entidades: "Excelente". "Ótimo para quem tem tempo de ajudar". "É ótimo, pois só de pensar que muitas pessoas estão felizes por aprender a ler e escrever". "É um trabalho que enriquece o professor através de capacitações e ao aluno através de palestras". "Bom, mas poderia melhorar". "É muito bom, apesar de ter alguns critérios não muito bem esclarecidos".

Os motivos que fundamentavam a boa avaliação eram a provisão de materiais e capacitação de professores.
Pelo fato de as aulas serem ministradas em instituições diferentes, o espaço físico no qual funcionavam apresentava diferenças significativas. O espaço das escolas era - melhor constituído para as finalidades de alfabetização. Pintado e cuidado, com carteiras novas ou em bom estado, boa luminação, com quadros e cartazes, e, às vezes, com desenhos infantis, por se trata de escolas para crianças.

lgrejas e associações, em geral, dispunham de salas para outros usos, destinadas, no caso, à alfabetização. Em quase todas, apesar disso, contavam com carteiras escolares; só em duas delas os alunos usavam cadeiras comuns e, em uma, sentavam-se sobre quatro ou cinco cadeiras empilhadas para chegar à mesa que, na verdade, era o altar da igreja. Na maioria, apesar de espaços não escolares, replicava-se a organização tradicional da sala, com as cadeiras em fila orientadas para o alfabetizador e o quadro. So em duas isso não acontecia, porque estavam reunidos ao redor de duas mesas; nos dois casos, as alfabetizadoras faziam com que os alunos trabalhassem em pequenos grupos, durante uma parte da aula. Em absolutamente todas as salas de aula visitadas havia quadro de giz, mesmo na igreja onde era usado o altar. Em algumas, não havia cartazes do alfabeto, embora sua necessidade tivesse sido destacada no curso de capacitação como indispensável para a construção de um ambiente alfabetizador; só a metade tinha visivelmente exposto esse recurso didático mportante. Havia cartazes nas paredes das salas: nas escolas, relacionados com ensino para crianças; em algumas igrejas, frases bíblicas; em associações, campanhas de saúde e outras temáticas de interesse comunitário. Em poucas delas apareciam produções feitas pelos alfabetizadores ou cartazes colocados pela professora. 
Talvez porque os espaços não fossem ad hoc nem sua principal função fosse a alfabetização, não se manifestava uma apropriação deles por parte das alfabetizadoras, nem a provisão por parte do Programa Alfabetização Solidária de materiais visuais didáticos específicos que indicassem sua presença e legitimassem as atividades. Assim, a alfabetização de adultos aparecia como uma função secundária, nas escolas, igrejas e associações comunitárias, uma atividade a mais, num espaço cedido. Não havia uma comunidade que absorvesse o Programa, mas um Programa que chegava de uma Instituição de Ensino Superior para ocupar um espaço que não era próprio e permanecia nele de uma forma marginal. No caso das associações, outras atividades em andamento, barulhentas, atrapalhavam o desenvolvimento das aulas. Nessas, a alfabetização evidenciava-se como uma atividade não inerente à cultura e aos fins principais desse lugar. Inseria-se na lógica institucional e cobria funções próprias dessa lógica.

No universo das salas visitadas, observaram-se algumas adaptações do Programa Alfabetização Solidária. Como disse anteriormente, as escolas ofereciam as melhores condições materiais para o desenvolvimento das aulas pela infra-estrutura ad hoc que possuem, tanto as estaduais quanto as municipais. Também, geralmente, as autoridades escolares estavam presentes podia comprovar-se uma inclusão dos alunos e das professoras do Programa na dinâmica de funcionamento escolar. Nas entrevistas com os alunos, percebia-se que os que realizavam sua alfabetização em escolas tinham mais intenções de continuar seus estudos e também achavam fácil a possibilidade de obter vaga e êxito nos seus planos. Numa das escolas visitadas, as alfabetizadoras estavam numa reunião com a diretora e todo o grupo de professoras e, em entrevista posterior, ressaltaram a ajuda e orientação recebidas durante todo o processo.

As associações de bairro, segundo uma entrevistada, "são muito comuns no município. Nos bairros carentes tendem a funcionar como uma articulação para reivindicar direitos. Assim, a alfabetização ajuda, porque vai sensibilizando e cobrando isso até na própria instituição". Nas visitas, era evidente que a alfabetização se incorporava nas atividades gerais, já que as recreativas e culturais eram o eixo das instituições. Emambas, os alunos não eramo público alvo "ideal" descrito pelo Programa. Em uma delas constituía-se de idosos já alfabetizados que realizavam outros cursos antes ou depois daquele: "Viemos aqui para passar o tempo, relembrar", afirmavam. Muitos tinham alcançado a $3^{\text {a }}$ série do antigo ensino primário7. Essa adaptação para idosos também incluía a realização de atividades manuais, tais como confecção de cartões postais.

Em outra associação visitada, também o público alvo não era o esperado: havia três idosos já alfabetizados e duas crianças que faziam reforço escolar com a professora. As atividades eram individualizadas. Assim, era clara a primazia da identidade institucional sobre os princípios do Programa Alfabetização
Solidária. Aliás, as associações dirigiam suas atividades de alfabetização para os seus sócios exclusivamente, sem incorporar outras pessoas da comunidade.

No entanto, houve uma sala visitada, cuja atividade era estritamente a alfabetização. Em uma sala bem diferente das usuais das associações, que parecia de uma escola uma alfabetizadora tinha um grupo de 18 pessoas, algumas já em seu $3^{\circ}$ semestre no Programa Alfabetização Solidária. Dois grupos de alunos predominavam: alguns que haviam chegado até $3^{\mathrm{a}}$ ou $4^{\mathrm{a}}$ série e outros que tinham freqüentado a escola poucos dias ou meses. Ali o eixo era a alfabetização e a professora, ela mesma estudando no $3^{\circ}$ ano do ensino médio, replicava seu modelo de aprendizagem, ordenando: "em silêncio", "preste atenção", "responda para mim". Nesse caso, os alunos de 28 até 45 anos, alguns deles desempregados, precisavam, sim, da alfabetização para trabalhar.

Por coincidência, em duas salas situadas em igrejas católicas aparecia a preocupação das alfabetizadoras com a continuidade de estudos dos seus alunos. Grande parte desse grupo, estava já há três anos com essas professoras, embora o Programa estivesse funcionando aí fazia dois semestres. Em uma delas, a ressignificação do Programa Alfabetização Solidária consistia em usálo para suas atividades de alfabetização funcional. A alfabetizadora fazia atividades diferenciadas por níveis. Utilizava um livro de $3^{a}$ série e trabalhava operações matemáticas (exercícios descontextualizados sem situações problemáticas). Sua experiência de vários anos nesse trabalho fazia com que encarasse criticamente o Programa. Havia vários anos que essas atividades eram realizadas na igreja, onde, inclusive, tinha funcionado uma tele-sala que depois fo transferida para uma escola. As professoras costumavam preparar os alunos para fazer a prova da $4^{a}$ série, para depois encaminhá os para uma escola. Reclamavam da falta de vagas em escolas para receber esses alunos e mostravam alguns deles que, tendo sido aprovados, continuavam na sala do Programa, esperando a oportunidade de ingressar nos cursos regulares.

"Incentivamos para continuar, não é só ler e escrever, não vou ensinar eles para aprender o nome. Mas gente incentiva e logo sente 0 bloqueio. Deram a prova, aprovaram e não têm vaga. Eu quero ir conversar com a Secretaria do Município, ir com os alunos. Temos 4 alunos daqui que acabaram a 4 série, tiraram o certificado e ainda permanecem aqui, porque não tem vaga. Fizeram o exame. Como a sal da escola está superlotada, eles mandam os alunos para o Centro, mas eles são carentes e não podem custear a condução» (Alfabetizadora).

No que diz respeito à duração prescrita pelo Programa, afirmavam: "Mas, o que eu vou falar para ela? Não pode continuar é só um semestre?" explicitando um consenso implícito, quase um pacto entre muitos dos envolvidos.

Numa outra sala, a alfabetizadora falava dos alunos que podiam passar para a $5^{\mathrm{a}}$ série assinalando os problemas que dificultavam essa continuidade: turno noturno, distância do domicílio, condição feminina. "As escolas só têm suplência à noite, os maridos ${ }^{8}$ não deixam e também é perigoso". "Tem $5^{a}$ série, mas à noite, então é difícil, a gente tem medo, mas dá para ir". 
Nenhuma das igrejas evangélicas respondeu ao questionário, portanto não foi possível comprovar os efeitos da parceria com a voz direta dessa fonte só com as observações. Nas visitas realizadas nessas igrejas, foi relatada por uma alfabetizadora (ela mesma membro da igreja) a existência de problemas com pastor que atrapalhavam o trabalho. Em um edifício muito amplo, de construção nova e com luxo, a sala destinada à alfabetização mudou de uma confortáve para uma pequena e incômoda argumentando-se que era devido ao custo de luz que era gasto nas aulas. A mesma pessoa relatou a negativa do pastor em permitir o ingresso de pessoas de fora da igreja e até a interferência dele no ensino intentando incluir conteúdos religiosos: "O pastor anterior queria que eu ensinasse com a Bíblia, mas este novo não intervém. Ele também restringiu só para as pessoas da igreja". Mesmo assim e apesar da grande quantidade de analfabetos nessa igreja, poucos assistiam às aulas de alfabetização ministradas ali.

Uma coordenadora (aluna da Instituição de Ensino Superior, evangélica) valorizava o caráter religioso como positivo na tarefa de alfabetização:

"Até no ensino, a gente sente, essa que ensina nas igrejas, tem uma formação religiosa, un jeito diferente de trabalhar, você sente também que é diferente por causa disso. Eu acho até interessante essa diferença, não porque elas traspassem a particularidade delas tudo com respeito à religião, não é isso, por exemplo, eles fazem umas orações antes de começar, até trabalham em temas bíblicos, acho isso interessante Embora não todos os alunos sejam evangélicos, paricipam. Faz parte da ige evangelicos, parlicipam. Faz parte da igreja evangélica, mas eles não se opõem. Até a parti de ali trabalhar alguma atividade, acho isso muito interessante"
Seja como for, a quantidade de alfabetizadores evangélicos era muito alta havia casos nos quais suas crenças incidiam no processo de ensino-aprendizagem. Em outros, embora o alfabetizador fosse membro da igreja, não se observou, durante as visitas, que esse fosse o eixo central do trabalho; muito pelo contrário, nos casos em que era professor, persistia essa outra identidade. Aliás, se era docente do ensino fundamental, era freqüente observar a utilização de textos mais aptos para o público infantil que para os adultos.

Notava-se, também, o desejo de ler a Bíblia e pregar como o objetivo e grande motivação de muitos dos alunos, questão que, por favorecer o processo de ensinoaprendizagem, pragmaticamente levava ao esquecimento, por parte dos diversos atores entrevistados, do caráter laico da proposta de alfabetização. Assim, a coordenadora geral da IES assinalava:

"A gente deixa claro que 0 espaço das salas de aula não é espaço de evangelização. Mas tem aquelas associações de moradores, políticas, também a gente cuida que 0 trabalho não $\mathrm{s}$ misture com essas questões. A gente bate forte 0 pé para não misturar, mas acontece".

Uma coordenadora (aluna da Instituição de Ensino Superior) conta:

"A única dificuldade que eu senti com uma das professoras foi que ela queria trabalhar a temática da saúde para o projeto cultural e os alunos, em função da igreja, eles têm algum problema de ir ao médico, eles acham que não precisam ir ao médico...

Um exemplo de atividade própria da instituição, na qual o trabalho do voluntário era pago com bolsa do Programa, foi o caso de um Asilo, uma instituição beneficente para idosos que recebiam moradia, alimentação e atenção médica, em troca de parte de sua aposentadoria. Os objetivos da instituição eram "alfabetizar e terapia ocupacional", questão que foiverificada navisita, destacando como um dos motivos para estabelecer-se a parceria a provisão de "recursos e materiais para os idosos". Na visita, observou-se o excelente trabalho da professora adequando as atividades para o nível de cada participante (muitos com sérios problemas de saúde), dois deles em claro processo de alfabetização.

Não se trata aqui de negar o direito à educação aos idosos, senão de destacar o processo de assimilação do Programa Alfabetização Solidária que algumas instituições realizavam, com a finalidade de obter financiamento e materiais para suas atividades. O caso daquele asilo era questionado pela própria equipe da IES: uma das professoras achava que: "só um conseguiu se alfabetizar. A alfabetização aí está servindo à auto-estima. Enquanto coordenadora pedagógicaeu deveriaatingir outro grupo". Embora uma integrante da sua equipe, justificasse: "quando visitamos o Asilo ficamos muito emocionados". Quando o semestre acabou, a parceria com o asilo não foi renovada.

Em síntese, as atividades-fim do Programa se adaptaram às demandas das instituições conveniadas, realizando atividades de terapia ocupacional, apoioescolar, acompanhamento a idosos, evangelização, escolarização e alfabetização funcional, atividades mportantes que deveriam ser realizadas por pessoas preparadas para isso, e não por alfabetizadores que receberam outro tipo de capacitação, com recursos (parte deles de caráter público) destinados para um outro objetivo. Assim, as IES transformam-se em prestadoras de serviços, tomando o lugar de outras agências que, por diversos motivos, não cumprem a sua função e, ante tantas necessidades não satisfeitas, acabaram por ocupar esse espaço, realizando tarefas que em grande parte das vezes, afastavam-se da finalidade do Programa.

Entretanto, há que se sublinhar que a realização de convênios com essas entidades, pela sua localização geográfica, permitiu uma maior capilaridade do Programa, ou seja, o acesso da população às aulas de alfabetização em locais distantes sem condições de sair do lugar por falta de meios de locomoção e de recursos econômicos para pagá-los.

Mas, percebeu-se, no decorrer do trabalho de campo, que essa abertura do Programa e das IES levava a uma aleatoriedade na distribuição das salas, na qual não era possível observar alguma correlação entre abertura de salas bolsões de analfabetismo, ou coordenação com outras IES que implementavam o mesmo Programa ou outros programas de alfabetização na região. Assim, embora as salas tivessem funcionamento efetivo não raro tinham poucos alunos, às vezes 3 ou 4 , embora tivessem começado com mais inscritos. Talvez a participação do poder público (municipal, estadual) ou de outros mecanismos de planejamento das atividades, visando atingir maior eficiência, permitisse otimizar as ações. Isto, também era mencionado no Projeto Nacional: coexistência de diferentes Instituições de Ensino Superior numa região, duplicando custos, ou a coordenação de IES de outros Estados em municípios próximos de IES sediadas no próprio Estado. Como exemplo pode-se citar o caso de uma Instituição com sede em um Estado do Nordeste, que coordenava salas na sua região (atuando também, em outros Estados), paralelamente a outra, de um outro Estado, que atuava em municípios limítrofes com a primeira. 
Aliás, o Programa Alfabetização Solidária, em alguns lugares da Zona Leste da Capital e da Grande São Paulo, concorria com outras alternativas de alfabetização de adultos. Assim, algumas das salas visitadas, situadas em igrejas e associações, alternavam o financiamento das suas tividades de alfabetização, (mas, também, de reforço e pós-alfabetização), que já realizavam anteriormente, entre o Programa o MOVA ${ }^{9}$, o IBEAC ${ }^{10}$ (Instituto Brasileiro de Estudos e Apoio Comunitário) e outra IES da região. Algumas dessas entidades, respondendo ao questionário enviado por mim, assinalavam a "vantagem comparativa do Programa Alfabetização Solidária" ante as outras fontes financiadoras: a provisão de materiais e o curso da Instituição de Ensino Superior. Também, em entrevistas:

"No próximo semestre vamos sair da 'Alfabetização Solidária'. Demora muito nos pagamentos, não recebemos ainda 0 dinheiro da merenda e a alfabetizadora também não recebeu a bolsa. 0 MOVA também não, é muito burocrático, olha aqui todos esses papéis que tem que preencher"r.

Até o ano desta pesquisa (2002), era possível verificar a prevalência da Instituição pesquisada, na região, na abertura de salas de aula em escolas, presumivelmente pelo fato de a Secretária de Educação ter sido coordenadora do Programa Alfabetização Solidária quando era professora do Departamento de Pedagogia dessa IES Também verificou-se em uma das escolas, no primeiro segmento da educação de jovens e adultos, a substituição da professora, com titulação e nomeada pelo município, por uma alfabetizadora. Dessa forma, poupava-se R $\$$ 800,00 entre um salário de $\mathrm{R} \$ 1.000,00$ (pago pelo município) e outro de $\mathrm{R} \$ 200,00$ (pago pelo Programa Alfabetização Solidária) Essa não foi uma situação generalizada, comprovando-se apenas em uma escola.

\section{Perfil dos alunos nas instituições "parceiras"}

A faixa etária dos 168 alunos das 19 salas do Projeto Grandes Centros Urbanos mostra que a população alvo do Programa Alfabetização Solidária, os jovens de 14 a 21 anos, era minoritária. Prevaleciam pessoas em idade de empregabilidade (22 até 39 anos) e idosos. A prevalência de pessoas idosas reflete o perfil histórico do analfabetismo brasileiro ${ }^{12}$

As pessoas, nas salas de aula da Zona Leste e de municípios do Alto Tietê em São $\mathrm{Paulo}^{13}$, nasceram no Sudeste ou provinham do Nordeste: "Nós

O Movimento de Alfabetização de Jovens e Adultos (MOVA) surgiu na cidade de São Paulo como uma experiência de parceria entre entidades representantes de movimentos populares e o governo municipal, (1989-1992), criando 1000 núcleos de alfabetização. A Secretaria Municipal de Educação provia recursins laborava o projeto político-pedagógico junto com os movimentos populares que cediam os espacos físicos para o funcionamento das aulas, matriculavam os educandos e selecionavam monitores e supervisores para participar da elaboraçãao do projeto político pedagógico.

MOVA centrou suas açoes na participaçao da população, visando construir a identidade dos educandos organização para viabilizá-las, assim como a deiversidade de idades, raça e gênero não seriam esementos contextuais na proposta, mas parte da alfabetização como processo mais abrangente, segundo a concepção de Paulo Freire (Pontual, 1997).

vamos alfabetizar no Nordeste, mas os nordestinos analfabetos estão aqui". (Coordenadora de IES). Dentre esses predominavam os pernambucanos $e$ os baianos. Mas, o Sudeste também estava altamente representado ( $45 \%$ dos entrevistados), com preponderância de mineiros e paulistas.

As profissões das pessoas entrevistadas mostravam a preponderância das donas de casa (35\%), seguidas por trabalhadores na ativa $(27 \%)$ e aposentados (14\%). Os restantes eram apenas estudantes, faziam bicos ou manifestavam outras situações.

As salas de alfabetização continham maior percentagem de mulheres $(57 \%)$ principalmente quando funcionavam em horários diurnos; nos horários noturnos predominavam os homens.

Considerando os alunos das salas situadas em escolas, aparece um perfil mais diferenciado: tratava-se de trabalhadores na ativa, entre os quais a quantidade de homens era igual a das mulheres, com vontade de continuar estudando, de preferência na própria escola.

- 33,5\% dos alfabetizandos nunca tinham ido à escola e 66,5\% a haviam freqüentado, mas muitos deles manifestavam que haviam passado por ela pouco tempo, apenas meses. Depois de adultos, $61 \%$ não tinham ido mais à escola, 20\% haviam passado menos de 1 ano na escola e $18 \%$ mais de um ano.

- $24 \%$ dos alunos já tinham participado do Programa Alfabetização Solidária mais de um semestre.

- $68 \%$ queriam continuar estudando depois da alfabetização, mas $27 \%$ só continuariamsefosse eno mesmo lugar onde estavam. No caso dos que estudavam em grejas ou associações, essa continuidade estava ameaçada, porque só poderia ser em escolas e essas tinham unicamente turnos noturnos ou estavam longe do local da alfabetização. O medo da violência tambén era um problema. Alguns manifestavam querer realizar exames supletivos.

Observou-se que as mulheres participavam mais freqüentemente de salas emigrejaseassociaçõesenosturnos diurnos, enquanto o público nas escolas e no noturno era preponderantemente de trabalhadores homens. Em comunidades mais isoladas e com menos opções, encontravam-se públicos mais heterogêneos.

\section{Considerações finais}

As Instituições de Ensino Superior, para a execução do Programa, implementavam salas de aula em vários locais. Além de escolas, a escolha incluía ONG de base: instituições sem fins lucrativos, religiosas ou de reivindicação de direitos, predominantemente igrejas e associações de moradores dos bairros. Essas entidades transferiam sua identidade institucional à implementação do Projeto, influindo na sua execução.

As escolas apresentavam-se como o melhor local para o desenvolvimento das aulas, embora outros elementos, como a situação geográfica e o fato de disponibilizar seu espaço físico só no período noturno, não thes permitisse cumprir com a intenção de levar o Programa aos bolsões de analfabetismo.

As igrejas, especialmente as católicas, mostravam uma tradição de alfabetização importante na hora do desenvolvimento das propostas, assim como bastante conhecimento sobre as dificuldades na continuidade dos estudos e iniciativa para tentar articular com o poder público a continuidade do processo de alfabetização. As pessoas 
que freqüentavam as igrejas evangélicas contavam com uma alta motivação para a alfabetização, pelo seu desejo de poder ler e, às vezes, pregar a Bíblia, só que, por ser esse o único objetivo, em geral manifestavam a intenção de não continuar seus estudos além das possibilidades oferecidas pelas próprias igrejas.

Já as associações de moradores apresentavam outras particularidades. Nelas era mais perceptível a incidência de sua identidade institucional sobre as atividades de alfabetização, inclusive usufruindo e adaptando a alfabetização aos seus fins e financiando outras atividades com fundos destinados à alfabetização.

Referências bibliográficas

BARREYRO, G. B. O "Programa Alfabetização Solidária": terceirização no contexto de reforma do Estado. In: $29^{\mathrm{a}}$ Reunião Anual da ANPED. Educação, cultura e conhecimento na contemporaneidade. Desafios e compromissos, Caxambu. 29a Reunião Anual

da ANPED. Educação, cultura e conhecimento na contemporaneidade. Desafios e compromissos. RJ : ANPED, p. 1-18. 2006

BRESSER PEREIRA, L. C. Da administração pública burocrática à gerencial. In BRESSER PEREIRA; Luiz Carlos e SPINK, Peter (orgs.) Reforma do Estado e administração pública gerencial. Rio de Janeiro: Fundação Getúlio Vargas, 1998.

CORAGGIO, J. L. Las propuestas del Banco Mundial para la educación In La educación según el Banco Mundial.Un análisis de sus propuestas y métodos. Buenos Aires: Miño y Dávila. p.11-68, 1997.

DI PIERRO, M. C. Descentralização, focalização e parceria: uma análise das tendências nas políticas públicas de educação de jovens e adultos. Educação e pesquisa, v. 27, n. 2 : 321-337, jul/dez. São Paulo, FEUSP, 2001.

FALCÃO, J. \& CUENCA, C. (org) Mudança social e reforma legal. Estudos para uma nova legislação do Terceiro Setor. Brasília: Consello da Comunidade Solidária: Unesco: BID, 1999 FRANCO, A. O caráter inovador dos Programas da Comunidade Solidária. Estratégias inovadoras de parceria no combate a exclusão social. Avaliação, diálogo e perspectivas. Seminário realizado pelo Conselho da Comunidade Solidária. Brasília: Comunidade SolidáriaUNESCO-PNUD, 2000

MINISTÉRIO DA EDUCAÇÃO. Brasil alfabetizado. www.mec.gov.br (acesso em 8/09/04)

PAULA, L. et al. Educação de jovens e adultos: a experiência da UFRRJ com o Programa

Alfabetização Solidária. Póster e resumo apresentados na 24a Reunião Anual da ANPED. GT n० 18, 2001.
PONTUAL, P. C. Desafios pedagógicos na construção de uma parceria: a experiência do MOVA-São Paulo (1989-1992). Alfabetização e cidadania. São Paulo: RAAAB, n. 5: 23-32, 1997

SAMPAIO, H. M. S. A construção e a dinâmica das parcerias da perspectiva das coordenações dos Programas Alfabetização, Capacitação e Universidade Solidária. (digitalizado). Versão preliminar de uma pesquisa qualitativa realizada pela autora para a UNESCO-Brasil, 1999.

TRIBUNAL DE CONTAS DA UNIÃO. Avaliação do TCU sobre a Alfabetização Solidária de Jovens e Adultos. Brasília: TCU, Secretaria de Fiscalização e Avaliação de Programas de Governo. (Sumário Executivo), 2003.

Documentos

Programa Alfabetização Solidária. Atendimento. www.alfabetizacao.org.br (acesso em 25/08/2004). Trajetória 8 anos. Brasília, 2004

Trajetória 6 anos. Brasília. 2002

Projeto Grandes Centros Urbanos. sem dados (dig)

Sites

http://www.alfabetizacaosolidaria.org.br e http://www.alfabetizacao.org.br, acesso entre 2000 e 2004 http://www.comunitas.org.br, acesso em 2003 e 2004

Recebido em julho de 2007

Aprovado em agosto de 2007 